\title{
PREVALENCE OF PSYCHIATRIC ILLNESS AND ITS RELATIONSHIP WITH DELINQUENT BEHAVIOUR- A STUDY AMONG INSTITUTIONALISED CHILDREN
}

\author{
Ganga Gangadhara Kaimal ${ }^{1}$
}

1Assistant Professor, Department of Psychiatry, Government TD Medical College, Alappuzha and Research Scholar, School of Behavioural Sciences, M. G. University, Kottayam.

ABSTRACT

\section{BACKGROUND}

Psychiatric disorders are common during childhood and adolescence. Studies have shown that behavioural problems and psychiatric morbidity are high among children placed in institutionalised settings and higher rates of delinquent behaviours were shown by children with psychiatric illness.

Aims-

1. To find out the prevalence of Psychiatric illness among inmates of orphanages.

2. To find out the relationship between Psychiatric illness and delinquent behaviour among inmates of orphanages.

\section{MATERIALS AND METHODS}

A cross-sectional study with a predetermined convenient sample size of 100 children and adolescents from orphanages in Kerala. Chi-square test is used for statistical analysis.

\section{RESULTS}

Of the 100 children assessed, 11 children were found to have Psychiatric illness. Among the 11 children, 3 children were suffering from emotional disorder, 2 each were suffering from behavioural disorder and developmental disorder and 6 children were suffering from substance use disorder. Substance use disorder was found to be a comorbidity. $12.3 \%$ of boys and $8.6 \%$ of girls were having psychiatric illness. Delinquent behaviours were found in 10 children. Among the 10 children who were having delinquent behaviour, 5 children (50\%) were suffering from psychiatric illness. Among the 90 children who were not showing delinquent behaviour, 6 children (6.7\%) were suffering from psychiatric illness. Statistical analysis was done using Chi-Square test and it was found that there is a significant difference in the psychiatric morbidity among children with delinquent behaviour compared to children without delinquent behaviour.

\section{CONCLUSION}

The inmates of orphanages suffer from a variety of mental health disorders. Delinquent behaviours were found among children living in orphanages. There was a significant difference in the psychiatric morbidity between children with or without delinquent behaviour.

\section{KEYWORDS}

Psychiatric Illness, Delinquent Behaviour, Orphanages.

HOW TO CITE THIS ARTICLE: Kaimal GG. Prevalence of psychiatric illness and its relationship with delinquent behaviour- A study among institutionalised children. J. Evolution Med. Dent. Sci. 2018;7(03):259-263, DOI: 10.14260/jemds/2018/58

\section{BACKGROUND}

Psychiatric disorders are common during childhood and adolescence. Studies by Humphreys et al, ${ }^{1}$ Jozefiak et $\mathrm{al}^{2}$ and Ståhlberg et $\mathrm{al}^{3}$ have shown that behavioural problems and psychiatric morbidity are high among children placed in institutionalised settings. Musisi et $\mathrm{al}^{4}$ conducted a comparative study on behavioural and emotional disorders of primary school-going orphans and non-orphans in Uganda. In this study, problem behaviours were seen in $45.1 \%$ of orphan children compared to $36.5 \%$ of non-orphan children. Bullying of other children and lying was found more in orphans. 13\% of orphans were involved in bullying compared with $10.6 \%$ of non-orphan children.

'Financial or Other Competing Interest': None.

Submission 01-12-2017, Peer Review 26-12-2017

Acceptance 01-01-2018, Published 13-01-2018.

Corresponding Author:

Dr. Ganga Gangadhara Kaimal,

Assistant Professor,

Department of Psychiatry,

Government TD Medical College, Alappuzha.

E-mail: gangagkaimal@gmail.com

DOI: $10.14260 /$ jemds $/ 2018 / 58$

\section{(c) (i) $\$$}

Other delinquent behaviours such as stealing things, destruction of property, truancy and frequent fights with other children were found more among non-orphan children, 72 of the 197 orphans and 49 of the 164 non-orphans were found to have psychiatric morbidity.

Elkington et $\mathrm{al}^{5}$ and Silva et $\mathrm{al}^{6}$ studied the relationship between delinquent behaviour and psychiatric illness and found higher rates of delinquent behaviours among children with psychiatric illness. Elkington et $\mathrm{al}^{4}$ conducted a longitudinal study to identify the prevalence of violence and the relationships between psychiatric disorders and violence among delinquent males and females, found that $34.6 \%$ of males and $19.8 \%$ of females had history of violence. $43.9 \%$ of males and $28.8 \%$ of females were violent in the subsample of people who were having psychiatric illness. The prevalence of violence in the subsample with no psychiatric disorder was $24.7 \%$ in males and $10.3 \%$ in females. Silva et al ${ }^{6}$ conducted a population study in Australia, found that 8\% boys and 3\% girls with Attention Deficit Hyperactivity Disorder had a community correction record. When compared Attention Deficit Hyperactivity Disorder children with children with no features of Attention Deficit Hyperactivity Disorder, it was found that boys with Attention Deficit Hyperactivity Disorder 
were two and half times and girls with Attention Deficit Hyperactivity Disorder were nearly three times more likely to have a community correction record.

Kaylor et al ${ }^{7}$ studied the behaviours of youth involved in the child welfare system found that older children were more likely to engage in delinquent behaviours than younger children. Boys were more likely to engage in delinquent behaviours than girls and children who were physically abused had more chance to engage in delinquent behaviours. They also found that increases in caregiver monitoring and good quality of relationship with caregivers were associated with decreases in delinquent behaviour.

The concept of the term juvenile delinquency is difficult to be stated. It has different meanings in different settings. Bartol and Bartol 8 defined juvenile delinquency as "a behaviour against the criminal code committed by an individual who has not reached adulthood, as defined by state or federal law" (p. 139). According to them, delinquency is an imprecise, nebulous, social, clinical and legal label for a wide variety of law and norm violating behaviours.

As per the crime statistics in India, ${ }^{9}$ in the year of 2015 , around 31000 juveniles were reported to be involved in conflict with law. This accounts approximately $1.1 \%$ of total cognisable crimes.

Psychiatrists usually diagnose the delinquent behaviours as part of conduct disorder or antisocial personality disorder. Children may get involved in delinquent behaviours such as theft as part of psychiatric disorders like Kleptomania. Adolescent children with manic episode may present with conduct symptoms. It is important to identify why a particular child is involving in a particular kind of behaviour in a particular situation. The interventions should be different if the delinquent behaviour occurs as a part of psychiatric illness.

\section{Aims}

1. To find out the prevalence of Psychiatric illness among inmates of orphanages.

2. To find out the relationship between Psychiatric illness and delinquent behaviour among inmates of orphanages.

\section{Objectives}

1. To identify the prevalence of Psychiatric illness among inmates of orphanages.

2. To identify the types of Psychiatric illness among inmates of orphanages.

3. To identify the gender difference in Psychiatric illness among inmates of orphanages.

4. To identify the prevalence of delinquent behaviour among inmates of orphanages.

5. To identify whether there is any relation between Psychiatric illness and delinquent behaviour among inmates of orphanages.

\section{MATERIALS AND METHODS}

\section{Study Design}

Cross-sectional study.

Sample- The sample consists of 100 children and adolescents from orphanages in Kerala. Sample size is decided to be of 100 children for convenience.

\section{Tools}

a. Personal data sheet- developed by the investigator.

b. Informal interview with children to assess delinquent behaviour.

c. Standard clinical interview to assess Psychiatric morbidity.

d. International Classification of Diseases -10 to diagnose Psychiatric illness.

\section{Study Period}

Between November 2013 and May 2017

\section{Tool Description}

Personal data sheet: - Developed by the investigator to collect the personal details of the sample. The items in the personal data sheets were name, age, gender, place of residence, history of delinquent behaviour, history of any substance use and history of psychiatric illness. ICD-10 classification of Mental and behavioural Disorders, Clinical descriptions and diagnostic guidelines which is a publication of World Health Organization is used to diagnose psychiatric illness.

\section{Procedure}

The Board of Control for Orphanages and other Charitable Homes in Kerala has been established as per State Government Gazette for the supervision and control of Homes in the State. There are 1205 registered orphanages in the state of Kerala with a sanctioned strength of 83716 inmates. The number of inmates in these homes were fifty-two thousand two hundred and ninety-two. ${ }^{10}$ After getting ethical clearance, three orphanages were selected randomly from the list of orphanages recognised by the control board under the social justice department of Kerala.

\section{Inclusion Criteria}

Children between 07 years to 18 years of age were included in the study.

\section{Exclusion Criteria}

Inmates below the age of 7 and above the age of 18 were excluded.

\section{Data Collection}

All the inmates in the age group of $7-18$ years of the two orphanages which were visited initially by the investigator and who gave consent to participate were included for the study. Children were selected randomly from the third orphanage to complete the predetermined sample size of 100 . Personal data of children was collected using a personal data sheet. The investigator interviewed each of the participant individually to assess delinquent behaviour and psychopathology. Psychiatric disorders were diagnosed based on ICD-10. Chi-square test is used for statistical analysis.

\section{RESULTS}

Out of the 100 children assessed, 11 children were found to have Psychiatric illness. Among the 11 children, 3 children were suffering from emotional disorder, 2 each were suffering from behavioural disorder and developmental disorder and 6 children were suffering from substance use disorder. Substance use disorder was found to be a comorbidity. It was found in one child with behavioural disorder and one child 
with developmental disorder. $12.3 \%$ of boys and $8.6 \%$ of girls were having psychiatric illness. Emotional disorders were more in girls. $60 \%$ of girls were suffering from emotional disorders. $75 \%$ of boys were found to have substance use disorder. Delinquent behaviours were found in 10 children. Of the 10 children, 8 were boys and 2 were girls. Among the 10 children who were having delinquent behaviour, 5 children (50\%) were suffering from psychiatric illness. 90 children of the total 100 children were not having delinquent behaviour. Among these 90 children, 6 children $(6.7 \%)$ were suffering from psychiatric illness. Statistical analysis was done using Pearson Chi-Square test and it was found that there is a significant difference in the psychiatric morbidity among children with delinquent behaviour compared to children without delinquent behaviour.

\section{Age Distribution of Children}

Of the 100 children, 27 were between 8-12 years of age and 73 were between 13-18 years of age.

\begin{tabular}{|c|c|c|}
\hline & Frequency & Percent \\
\hline 8-12 years & 27 & 27.0 \\
\hline 13-18 years & 73 & 73.0 \\
\hline Total Table 1. Age Distribution \\
\hline \multicolumn{2}{|c|}{} \\
\hline
\end{tabular}

\section{Gender Distribution of Children}

Of the 100 children, there were 65 boys and 35 girls.

\begin{tabular}{|c|c|c|}
\hline Gender & Frequency & Percent \\
\hline Male & 65 & 65.0 \\
\hline Female & 35 & 35.0 \\
\hline Total Table 2. Gender Distribution \\
\hline \multicolumn{2}{|c|}{} \\
\hline
\end{tabular}

\section{Prevalence of Psychiatric Illness}

11 percent of the inmates were found to have Psychiatric illness.

\begin{tabular}{|c|c|c|}
\hline Psychiatric Illness & Frequency & Percent \\
\hline Present & 11 & 11.0 \\
\hline Absent & 89 & 89.0 \\
\hline Total & $\mathbf{1 0 0}$ & $\mathbf{1 0 0 . 0}$ \\
\hline \multicolumn{2}{|c|}{ Table 3. Psychiatric Illness } \\
\hline
\end{tabular}

\section{Types of psychiatric illness}

Substance use disorders were the most commonly seen psychiatric illness. $46.2 \%$ of children had substance use disorder, $23.1 \%$ of children had emotional disorder and $15.4 \%$ of children had behavioural disorder and developmental disorder.

\begin{tabular}{|c|c|}
\hline Type of Psychiatric Illness & $\begin{array}{c}\text { Number of Children } \\
\text { Affected }\end{array}$ \\
\hline Emotional disorders & $3(23.1 \%)$ \\
\hline Behavioural disorders & $2(15.4 \%)$ \\
\hline Developmental disorders & $2(15.4 \%)$ \\
\hline Substance use disorder & $6(46.2 \%)$ \\
\hline \multicolumn{2}{|c|}{ Table 4. Types of Psychiatric Illness }
\end{tabular}

\section{Comorbidity}

Substance use disorder was found to be a common comorbidity. It was found in one child with behavioural disorder and one child with developmental disorder.

\section{Gender and Psychiatric Illness}

Psychiatric illness was present in $12.3 \%$ of boys and $8.6 \%$ of girls. Pearson Chi-Square test was used for statistical analysis and $\mathrm{p}$ value was found to be 0.569 . There was no significant difference between boys and girls in having psychiatric illness.

\begin{tabular}{|c|c|c|c|}
\hline Gender & $\begin{array}{c}\text { Psychiatric } \\
\text { Illness } \\
\text { Present }\end{array}$ & $\begin{array}{c}\text { Psychiatric } \\
\text { Illness Absent }\end{array}$ & Total \\
\hline Boys & $8(12.3 \%)$ & $57(87.7 \%)$ & $\mathbf{6 5}(\mathbf{1 0 0 \% )}$ \\
\hline Girls & $3(8.6 \%)$ & $32(91.4 \%)$ & $\mathbf{3 5 ( 1 0 0 \% )}$ \\
\hline Total & $11(11 \%)$ & $89(89 \%)$ & $\mathbf{1 0 0}(\mathbf{1 0 0 \% )}$ \\
\hline \multicolumn{4}{|c}{ Table 5. Gender and Psychiatric Illness } \\
\hline
\end{tabular}

\section{Gender and type of psychiatric Illness}

Emotional disorders were more in girls and substance use disorders were more seen in boys. Statistical analysis was done by chi-square test and $p$ value was 0.039 which indicates that there was a significant difference in the pattern of psychiatric illness between boys and girls.

\begin{tabular}{|c|c|c|c|c|c|}
\hline Gender & Emotional Disorder & Behavioural Disorder & Developmental Disorder & Substance Use Disorder & Total \\
\hline Boys & 0 & $1(12.5 \%)$ & $1(12.5 \%)$ & $6(75 \%)$ & 8 \\
\hline Girls & $3(60 \%)$ & $1(20 \%)$ & $1(20 \%)$ & 0 & 5 \\
\hline Total & $\mathbf{3 ( 2 3 . 1 \% )}$ & $\mathbf{2 ( 1 5 . 4 \% )}$ & $\mathbf{2 ( 1 5 . 4 \% )}$ & $\mathbf{6 ( 4 6 . 2 \% )}$ & $\mathbf{1 3}$ \\
\hline
\end{tabular}

Table 6. Gender and Type of Psychiatric Illness

\section{Prevalence of Delinquent Behaviour}

Of the 100 children, delinquent behaviour was present in 10 children.

\begin{tabular}{|c|c|c|}
\hline Delinquent Behaviour & Frequency & Percentage \\
\hline Present & 10 & 10.0 \\
\hline Absent & 90 & 90.0 \\
\hline \multicolumn{2}{|c|}{ Table 7. Delinquent Behaviour } \\
\hline
\end{tabular}

\section{Age and Delinquent Behaviour}

Delinquent behaviour was seen more in older children. $80 \%$ of children with delinquent behaviour was in the age group
13-18 years and $20 \%$ of children was in the age group of $8-12$ years.

\begin{tabular}{|c|c|}
\hline Age & Delinquent Behaviour \\
\hline 8-12 years & $2(20 \%)$ \\
\hline 13-18 years & $8(80 \%)$ \\
\hline Total & $\mathbf{1 0}(\mathbf{1 0 0} \%)$ \\
\hline Table 8. Age and Delinquent Behaviour \\
\hline
\end{tabular}

\section{Gender and Delinquent Behaviour}

$12.3 \%$ of boys and $5.7 \%$ of girls were having delinquent behaviour. Among children with delinquent behaviour, $80 \%$ were boys and $20 \%$ were girls. Chi-square test was done, and $\mathrm{p}$ value was found to be 0.295 . No significant difference was 
found between boys and girls in exhibiting delinquent behaviour.

\begin{tabular}{|c|c|c|c|}
\hline Gender & $\begin{array}{c}\text { Delinquent } \\
\text { behaviour } \\
\text { present }\end{array}$ & $\begin{array}{c}\text { Delinquent } \\
\text { behaviour } \\
\text { absent }\end{array}$ & Total \\
\hline Boys & $8(12.3 \%)$ & $57(87.7 \%)$ & $\mathbf{6 5}$ \\
\hline Girls & $2(5.7 \%)$ & $33(94.3 \%)$ & $\mathbf{3 5}$ \\
\hline Total & $10(10 \%)$ & $\mathbf{9 0}(\mathbf{9 0} \%)$ & $\mathbf{1 0 0}$ \\
\hline \multicolumn{3}{|c|}{ Table 9. Gender and Delinquent Behaviour } \\
\hline
\end{tabular}

Psychiatric illness and delinquent behaviour:

Among the 10 children who were having delinquent behaviour, 5 (50.0\%) children were suffering from psychiatric illness.

\begin{tabular}{|c|c|c|}
\hline Children with delinquent behaviour & 10 & \\
\hline Children with Psychiatric illness & 5 & $50 \%$ \\
\hline Children without psychiatric illness & 5 & $50 \%$ \\
\hline Table 10. Psychiatric Morbidity in Children with \\
Delinquent Children \\
\hline
\end{tabular}

Psychiatric morbidity in children without delinquent behaviour:

$6(6.7 \%)$ among the 90 children without delinquent behaviour, were suffering from psychiatric illness.

\begin{tabular}{|c|c|c|}
\hline Children without delinquent behaviour & 90 & \\
\hline Children with psychiatric illness & 6 & $6.7 \%$ \\
\hline Children without psychiatric illness & 84 & $93.3 \%$ \\
\hline Table 11. Psychiatric Morbidity in Children without \\
Delinquent Behaviour \\
\hline
\end{tabular}

Relationship between delinquent behaviour and psychiatric illness: $50.0 \%$ of the children with delinquent behaviour were suffering from psychiatric illness whereas $6.7 \%$ of children without delinquent behaviour were suffering from psychiatric illness. Psychiatric morbidity was high among children who were showing delinquent behaviour. Statistical analysis was done using Pearson ChiSquare test. Pearson Chi-square value was 17.263 and $p$ value was less than 0.001 . There was a significant difference in the psychiatric morbidity among children with delinquent behaviour compared to children without delinquent behaviour.

\begin{tabular}{|c|c|c|c|}
\hline & $\begin{array}{c}\text { Children with } \\
\text { Psychiatric } \\
\text { Illness }\end{array}$ & $\begin{array}{c}\text { Children without } \\
\text { Psychiatric } \\
\text { Illness }\end{array}$ & Total \\
\hline $\begin{array}{c}\text { Children with } \\
\text { delinquent } \\
\text { behaviour }\end{array}$ & $5(50.0 \%)$ & $5(50.0 \%)$ & $\mathbf{1 0}$ \\
$\begin{array}{c}\text { Children without } \\
\text { delinquent } \\
\text { behaviour }\end{array}$ & $6(6.7 \%)$ & $84(93.3 \%)$ & $\mathbf{9 0}$ \\
\hline \multicolumn{2}{|c|}{ Table 12. Relationship between Delinquent } \\
Behaviour and Psychiatric Illness
\end{tabular}

\section{DISCUSSION}

This study sampled 100 children and adolescents from orphanages in Kerala. Most of the children (73\%) were in the age group of 13-18 years. Boys constitute majority (65\%) of the sample. $11 \%$ of the inmates were found to have psychiatric illness. $12.3 \%$ of boys and $8.6 \%$ of girls were suffering from psychiatric illness. Earlier studies by Humphreys et $\mathrm{al}^{1}$ and Jozefiak et $\mathrm{al}^{2}$ showed high rates of psychiatric morbidity among institutionalised children. Humphreys et al ${ }^{1}$ conducted a randomised control trial in Romania, found that $44 \%$ of institutionalised children had psychiatric illness. Among institutionalised boys, the rates of psychiatric illness were $45 \%$ and in girls the rates were $33 \%$. Jozefiak et $\mathrm{al}^{2}$ in their study among adolescents living in residential youth care at Norway found $76.2 \%$ of the youth fulfilled the criteria for at least one DSM-IV diagnosis during the previous 3 months. The finding of the present study is not consistent with the earlier findings. This may be due to the higher quality of care provided in the institutions. Kerala has health and social standards that is in comparison with developed countries. The orphanages selected for this study are the orphanages registered under the social welfare department. Due to the strict laws and regulations that is existing in the state of Kerala, the care provided by the institutions to its inmates are under regular scrutiny. The reason for the low prevalence of psychiatric morbidity among inmates of orphanages in this study may due to the good quality of care that the children are receiving.

In the present study, emotional disorders were more in girls. Among boys the commonest diagnosis was substance use disorder. This finding is consistent with the studies by Jozefiak et $\mathrm{al}^{2}$ in which girls had 2.5-3 times higher odds for depressive and anxiety disorders and boys had higher rates for conduct disorder. Teplin et al ${ }^{11}$ in their study among 1829 detained youth in Illinois found that nearly two thirds of males and three quarters of females met diagnostic criteria for one or more psychiatric disorders and half of males and almost half of females had a substance use disorder. More than $40 \%$ of males and females met criteria for disruptive behaviour disorders and more than $20 \%$ of females met criteria for a major depressive episode.

Delinquent behaviour was present in $10 \%$ of children. $12.3 \%$ of boys and $5.7 \%$ of girls were showing delinquent behaviour. $80 \%$ of children with delinquent behaviour was in the age group of 13-18 years. This finding was consistent with the study by Kaylor et $\mathrm{al}^{7}$ where boys were more likely to engage in delinquent behaviours than girls and older children were more likely to engage in delinquent behaviours than younger children.

$50 \%$ of children with delinquent behaviour were having psychiatric illness and only $6.7 \%$ of children without delinquent behaviour were having psychiatric illness. This is consistent with the study by Ståhlberg et al, ${ }^{3}$ Elkington et al, ${ }^{5}$ Silva et $\mathrm{al}^{6}{ }^{6}$ and Teplin et $\mathrm{al}^{11}$ where high rates of psychiatric morbidity were found among children who were showing problematic behaviours and who had come in contact with juvenile justice systems.

\section{CONCLUSION}

The inmates of orphanages suffer from a variety of mental health disorders. Substance use disorders were found more in boys and emotional disorders were found more in girls. Delinquent behaviours were found among children living in orphanages. There was a significant difference in the psychiatric morbidity between children with or without delinquent behaviour. As there is a significant difference in psychiatric morbidity between children with or without delinquent behaviour, more importance should be given to 
identify whether the delinquent behaviour occurs as a part of psychiatric illness. If the delinquent behaviour is a consequence of psychiatric morbidity, interventions should be different. Both boys and girls need mental health services equally. This study presents certain basic data that can help the policy makers to understand the importance of mental health assessment and interventions in institutions such as orphanages.

\section{Limitations}

- Small sample size.

- No interventions were planned.

\section{Recommendations}

Studies with larger sample size should be conducted in institutions like orphanages to identify the prevalence of psychiatric illness and delinquent behaviours. Gender difference in delinquent behaviour and relationship of delinquent behaviour to each type of psychiatric illness needs to be studied. Appropriate interventions should be planned and given to the children, and effectiveness of interventional strategies should be researched.

\section{REFERENCES}

[1] Humphreys KL, Gleason MM, Drury SS, et al. Effects of institutional rearing and foster care on psychopathology at age 12 years in Romania: followup of an open, randomised controlled trial. Lancet Psychiatry 2015;2(7):625-34.

[2] Jozefiak T, Kayed NS, Rimehaug T, et al. Prevalence and comorbidity of mental disorders among adolescents living in residential youth care. Eur Child Adolesc Psychiatry 2016;25(1):33-47.
[3] Ståhlberg 0, Anckarsäter H, Nilsson T. Mental health problems in youths committed to juvenile institutions: prevalences and treatment needs. Eur Child Adolesc Psychiatry 2010;19(12):893-903.

[4] Musisi S, Kinyanda E, Nakasujja N, et al. A comparison of the behavioral and emotional disorders of primary school-going orphans and non-orphans in Uganda. African Health Sciences 2007;7(4):202-13.

[5] Elkington KS, Teplin LA, Abram KM, et al. Psychiatric disorders and violence: a longitudinal study of delinquent females and males after detention. J Am Acad Child Adolesc Psychiatry 2015;54(4):302-12.e5.

[6] Silva D, Colvin L, Glauert R, et al. Contact with the juvenile justice system in children treated with stimulant medication for attention deficit hyperactivity disorder: a population study. The lancet Psychiatry 2014;1(4):278-85.

[7] Grogan-Kaylor A, Ruffolo MC, Ortega RM, et al. Behaviors of youth involved in the child welfare system. Child Abuse \& Neglect 2008;32(1):35-49.

[8] Bartol CR, Bartol AM. Criminal behavior: a psychological approach. 9th edn. Upper Saddle River, New Jersey: Pearson Prentice Hall 2011.

[9] Crime in India 2015 statistics. http://ncrb.nic.in/StatPublications/ CII/CII2015/FILES/Statistics-2015_rev1_1.pdf.

[10] List of institutions recognized by the control board as on $\quad 07-10-2015 \quad$ orphanages. http://www.swd.kerala.gov.in/index.php/orphanages.

[11] Teplin LA, Abram KM, McClelland GM, et al. Psychiatric disorders in youth in juvenile detention. Arch Gen Psychiatry 2002;59(12):1133-43. 